\title{
OPEN Leaf surface characteristics affect the deposition and distribution of droplets in rice (Oryza sativa L.)
}

\author{
Guangmei $\mathrm{Ji}^{1,2,3}$, Huizhe Chen ${ }^{2}$, Yuping Zhang ${ }^{2}$, Jing Xiang ${ }^{2}$, Yaliang Wang ${ }^{2}$, Zhigang Wang ${ }^{2}$, \\ Defeng Zhu ${ }^{2 \bowtie}$ \& Yikai Zhang ${ }^{2 \bowtie}$
}

We studied the effects of leaf surface characteristics on canopy droplet behaviour using two rice cultivars with similar leaf shapes but significantly different leaf surface characteristics: Jia58 (glabrous rice; smooth leaf surface and no burrs) and Yongyou12 (hairy-leaved rice; rough leaf surface covered with burrs). The plants were subjected to spray tests with different spray pressures and nozzle apertures. The results showed that the deposition amount per unit leaf area was significantly higher in the Yongyou12 canopy than in the Jia58 canopy. The diameter, volume median diameter, number median diameter, and coverage of droplets were significantly higher in Yongyou12 than in Jia58, while the coverage density of droplets was significantly lower. The proportion of small droplets of Jia58 is higher than that of Yongyou12. Thus, a larger amount of large-sized droplets could retain on the leaf surface of hairy-leaved rice, and a larger number of small-sized droplets were retained on the leaf surface of glabrous rice. Smaller pressure and larger flow nozzle were conducive to the retention of the Jia58, while Yongyou12 required larger pressure and larger flow nozzles. Ultrastructural analyses revealed that the leaf surface of glabrous rice had no trichomes and more wax than hairy-leaved rice, and the critical surface tension was lower, resulting in the retention of mainly small droplets on its leaf surface and a lower deposition amount. Therefore, in order to increase the deposition of pesticide droplets on the leaf surface in production, glabrous rice should choose nozzles with smaller spray pressure and large flow rate.

Rice is one of the most important food crops in China, and its planting area and total production are important for China's food production and food security ${ }^{1}$. However, diseases, insects, grass weeds, and other biological factors are affecting the stable and high yield of rice in China ${ }^{2,3}$. The annual yield loss of rice in China due to pests and diseases is about 4 million tons ${ }^{4,5}$. Chemical pesticides are the main pest control method used in rice production, and the area of pesticide use in China amounts to more than 167 million hectares per year ${ }^{6,7}$. Due to sub-optimal application technologies, a large amount of pesticide is not delivered to the right place or is unevenly applied. This reduces its effectiveness to control pests, and results in the waste of pesticides and pollution of soil and water. In China, the annual pesticide-contaminated area is 13.3 million hectares, accounting for more than one-seventh of the national arable land ${ }^{8}$. Therefore, improving application technologies and increasing the utilization rate of pesticides is a priority for China's food production. In addition to the spraying machinery, application methods, and pesticide composition, the effective use of pesticides also depends on the leaf morphology of crop plants $^{9}$. Diseases and insects occur at different times and in different parts of rice plants ${ }^{10}$. Because plant height and leaf morphology differ among rice varieties, pesticides need to be applied considering these characteristics and the site where diseases and insects occur ${ }^{11}$. It has been shown that the droplet deposition amount is significantly affected by leaf surface properties and leaf inclination angle ${ }^{12}$. Nozzle type, size and pressure also affect the amount of deposition on crop leaves ${ }^{13}$. The amount of pesticide deposited on the leaf is closely related to the effectiveness of pest and disease control. However, no previous studies have focused on differences in the deposition and distribution of pesticides on the leaf among varieties with different leaf surface characteristics. In the present study, we selected glabrous rice ${ }^{14}$ (a dominant rice species with smooth leaves, stem sheaths, and rice grains) and hairy-leaved rice with a similar leaf shape but significantly different leaf surface characteristics, and applied a liquid with different spray pressure and nozzle aperture. This allowed us to compare the deposition

${ }^{1}$ College of Agronomy, Jiangxi Agricultural University, Nanchang, Jiangxi 330045, People's Republic of China. ${ }^{2}$ State Key Laboratory of Rice Biology, China National Rice Research Institute, Hangzhou, Zhejiang 310006, People's Republic of China. ${ }^{3}$ Guizhou Rice Research Institute, Guiyang, Guizhou 550009, People's Republic of China. ${ }^{\otimes}$ email: cnrice@qq.com; yikaizhang168@163.com 


\begin{tabular}{|l|c|l|l|l|l|l|}
\hline $\begin{array}{l}\text { Sources of } \\
\text { variation }\end{array}$ & Deposition rate & $\begin{array}{l}\text { Droplet coverage } \\
\text { density }\end{array}$ & $\begin{array}{l}\text { Droplet coverage } \\
\text { rate }\end{array}$ & Droplet diameter & $\begin{array}{l}\text { Number middle } \\
\text { diameter }\end{array}$ & $\begin{array}{l}\text { Volume middle } \\
\text { diameter }\end{array}$ \\
\hline Genotype (G) & $10.09^{* *}$ & $864.11^{* * *}$ & $237.35^{* * *}$ & $122.65^{* * *}$ & $97.77^{* * *}$ & $38.36^{* * *}$ \\
\hline Spray pressure (P) & $80.19^{* * *}$ & $33.54^{* *}$ & $52.51^{* * *}$ & $19.18^{* * *}$ & $1.76 \mathrm{NS}$ & $0.02 \mathrm{NS}$ \\
\hline Nozzle size (S) & $1021.79^{* * *}$ & $3.21 \mathrm{NS}$ & $99.86^{* * *}$ & $8.54^{* *}$ & $4.12^{\star}$ & $7.38^{* *}$ \\
\hline $\mathrm{G} \times \mathrm{P}$ & $0.56^{\mathrm{NS}}$ & $189.98^{* * *}$ & $4.81^{*}$ & $14.14^{* * *}$ & $1.41^{\mathrm{NS}}$ & $0.009^{\mathrm{NS}}$ \\
\hline $\mathrm{G} \times \mathrm{S}$ & $0.34^{\mathrm{NS}}$ & $27.48^{* * *}$ & $36.29^{* * *}$ & $5.49^{*}$ & $1.86^{\mathrm{NS}}$ & $0.61^{\mathrm{NS}}$ \\
\hline $\mathrm{P} \times \mathrm{S}$ & $99.23^{* * *}$ & $129.84^{* * *}$ & $21.55^{* * *}$ & $4.51^{*}$ & $1.46^{\mathrm{NS}}$ & $2.59^{\mathrm{NS}}$ \\
\hline $\mathrm{G} \times \mathrm{P} \times \mathrm{S}$ & $0.24^{\mathrm{NS}}$ & $4.11^{*}$ & $26.14^{* * *}$ & $14.62^{* * *}$ & $7.96^{* *}$ & $4.36^{*}$ \\
\hline
\end{tabular}

Table 1. Results of ANOVA in the rice deposition and distribution of droplets. NS not significant. ${ }^{\star}$ Denotes significance at the $\mathrm{P} \leq 0.05$ level. ${ }^{* *}$ Denotes significance at the $\mathrm{P} \leq 0.01$ level. ${ }^{* *}$ Denotes significance at the $\mathrm{P} \leq 0.001$ level.

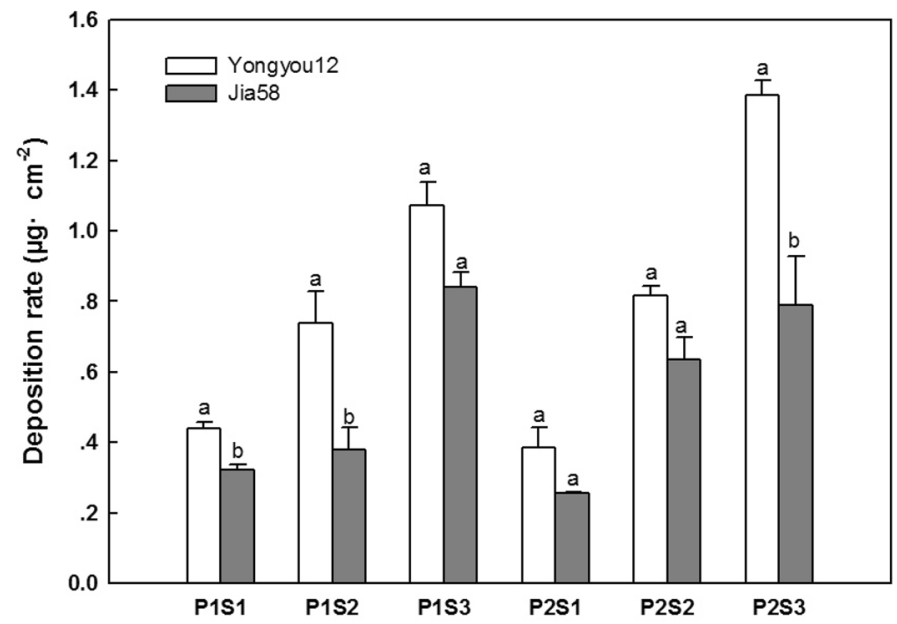

Figure 1. Droplets deposition on the canopy leaves of two rice varieties. The different letters means significant difference $(P \leq 0.01)$ by t-tests.

of spray droplets between these two varieties, and to study the behaviour of canopy droplets on rice plants with different leaf surface characteristics. Ultimately, our results provide a basis for the improvement of spraying technology to reduce the amount of pesticide applied and improve its utilization.

\section{Results}

Droplet deposition on leaf canopy. Spray pressure and nozzle aperture are the key factors affecting droplet deposition on the canopy of rice, and the deposition pattern of droplets on the canopy is closely related to the leaf surface characteristics. Under the same spraying conditions, the deposition amount per unit leaf area was significantly higher in Yongyou12 with hairy leaf than in Jia58 with hairless leaf (Table 1, Fig. 1). The deposition per unit area of Yongyou 12 was $0.81 \mu \mathrm{g} \mathrm{cm}^{-2}$, while that of Jia58 was only $0.54 \mu \mathrm{g} \mathrm{cm}^{-2}$. With the increase of spray pressure, the deposition amount of Yongyou12 and Jia58 increased by $0.11 \mu \mathrm{g} \mathrm{cm}^{-2}$ and $0.05 \mu \mathrm{g} \mathrm{cm}^{-2}$, respectively, and the difference was not significant. Under the same spray pressure, the deposition of canopy droplets in both rice varieties increased significantly with increasing nozzle aperture. As the nozzle becomes larger, the deposition volume of Yongyou 12 increased by $0.36 \mu \mathrm{g} \mathrm{cm}^{-2}$ and $0.45 \mu \mathrm{g} \mathrm{cm}^{-2}$, respectively, while the deposition volume of Jia58 increased by $0.22 \mu \mathrm{g} \mathrm{cm}^{-2}$ and $0.31 \mu \mathrm{g} \mathrm{cm}^{-2}$ respectively. Comparison of deposition under different conditions revealed that Yongyou 12 received $1.39 \mu \mathrm{g} \mathrm{cm}^{-2}$ canopy droplets per unit area under the optimal deposition condition P2S3, while Jia58 received $0.84 \mu \mathrm{g} \mathrm{cm}^{-2}$ of canopy droplets per unit area under the optimal deposition condition P1S3. Therefore, in the actual spraying operation, glabrous rice should be sprayed with a nozzle with a lower spray pressure and a larger flow rate, which is more conducive to the deposition of pesticide drops on the surface of the blade.

Droplet distribution in leaf canopy. The droplet coverage density was significantly lower in Yongyou12 than in Jia58 (Table 1, Fig. 2A). For Yongyou12, the larger spray pressure increased the droplet coverage density, while the larger spray pressure of Jia58 is not conducive to the droplet coverage. Under low spray pressure, the higher nozzle flow rate promoted the increase in the leaf droplet coverage density of the two genotypes of rice, while the higher nozzle flow rate reduced the leaf droplet coverage density of the two varieties with high spray pressure. However, droplet coverage was higher in Yongyou12 than in Jia58 (Table 1, Fig. 2B). Simi- 

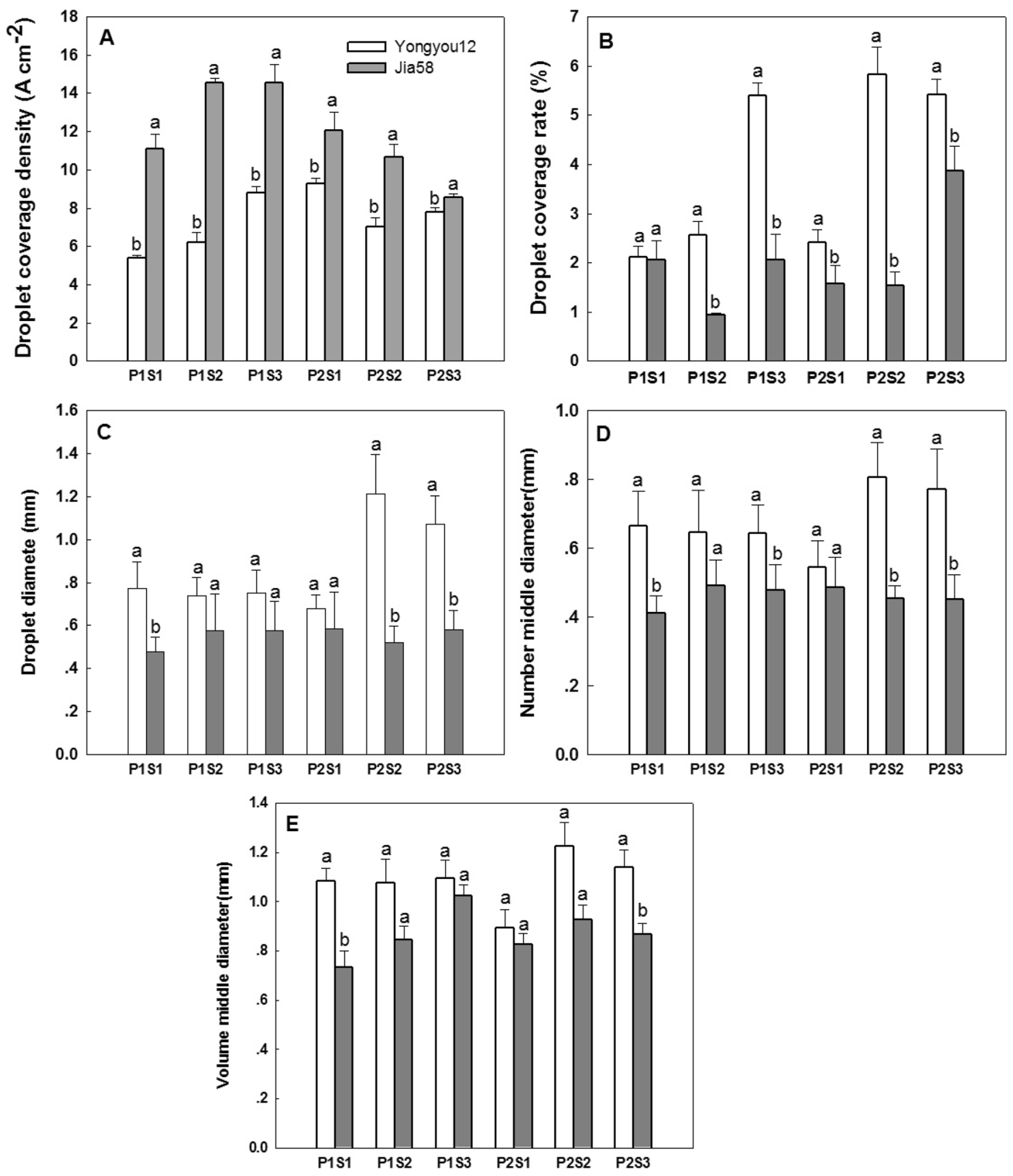

Figure 2. Distribution of droplets on the canopy leaves of two rice varieties. The different letters means significant difference $(P \leq 0.01)$ by t-tests.

larly, the droplet diameters (Fig. 2C), the number median diameter (Fig. 2D) and the volume median diameter (Fig. 2E) were larger for Yongyou12 than for Jia58. For both varieties, the volume median diameter of droplets was much larger than the droplet diameters and the number median diameter of droplets. The three diameters of Yongyou12 showed an increasing trend with increased spraying pressure and nozzle aperture, but those of Jia58 were not significant. Therefore, a larger amount of larger-sized droplets could retained on the leaf surface of Yongyou12, but a larger number of smaller-sized droplets were retained on the leaf surface of Jia58.

Droplet size in leaf canopy. According to the average droplet diameter, the droplets formed on the leaf canopy surface after spraying can be classified into different groups. This clarifies the dynamics and variability of droplet distribution of different particle sizes, and is the key to understanding the uniformity of droplet distribution in the canopy. As shown in Table 2, the proportion of small droplets (D1) of Yongyou12 was lower than Jia58 while the proportion of large droplets (D3) of Yongyou12 was higher than Jia58, and the droplet uniformity (D2) was Yongyou12 higher than Jia58. For Yongyou12, as the spray pressure increased, the number of droplets in the D1 and D3 groups decreased while the number of droplets in the D2 groups increased, i.e., the droplet uniformity increased. For Jia58, as the spray pressure increased, the droplet size distribution law was opposite to 


\begin{tabular}{|l|l|l|l|l|l|l|}
\hline \multirow{2}{*}{ Treatment } & \multicolumn{2}{|l|}{ D1 (\%) } & \multicolumn{2}{l|}{ D2 (\%) } & D3 (\%) \\
\cline { 2 - 7 } & Yongyou12 & Jia58 & Yongyou12 & Jia58 & Yongyou12 & Jia58 \\
\hline P1S1 & 41.53 & 46.66 & 48.20 & 46.79 & 10.27 & 6.55 \\
\hline P1S2 & 44.96 & 51.95 & 42.78 & 40.02 & 12.25 & 8.03 \\
\hline P1S3 & 43.02 & 48.51 & 45.91 & 43.67 & 11.08 & 7.82 \\
\hline P2S1 & 39.47 & 55.18 & 52.44 & 35.60 & 8.09 & 9.22 \\
\hline P2S2 & 40.10 & 49.35 & 50.77 & 44.03 & 9.14 & 6.61 \\
\hline P2S3 & 38.25 & 52.59 & 53.93 & 40.05 & 7.82 & 7.35 \\
\hline
\end{tabular}

Table 2. Rice canopy different size distribution of droplets. The average diameter of all droplets is $\mathrm{D}$, grouped by $0-80 \% \mathrm{D}, 80-160 \% \mathrm{D},>160 \% \mathrm{D}$ (numbers are $\mathrm{D} 1, \mathrm{D} 2, \mathrm{D} 3)$.

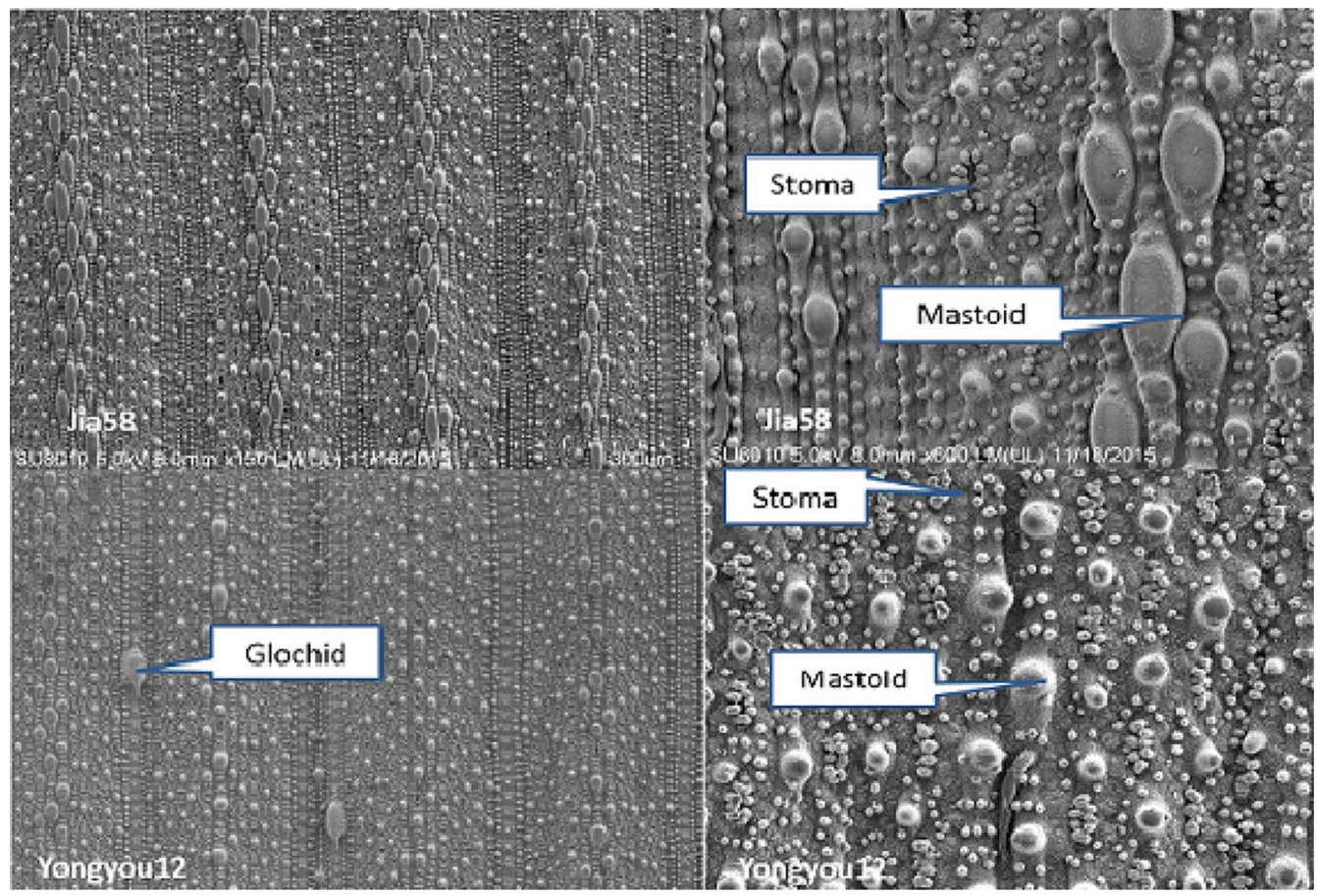

Figure 3. Scanning electron microscope(SEM)photos of two rice varieties. $100 \mu \mathrm{m}$ and $50 \mu \mathrm{m}$ are mage scale, is under 3000 times and 6000 times the figure.

that of Yongyou12. The nozzle aperture did not significantly affect the pattern of droplet uniformity. Yongyou12 had the highest droplet uniformity under P2S3 treatment, while Jia58 had the highest droplet uniformity under P1S1 treatment. Therefore, compared with hairy rice, the leaf surface of glabrous rice was easier to retain small droplets, and the droplet uniformity was lower.

Ultrastructure of rice leaf surface. The leaf surface structure varies greatly among different types of rice varieties. As shown in Fig. 3, the leaf surface of Yongyou12 is densely covered with papillae, stomata, and other microstructures, and the papillae have a rough surface, are mainly spherical, and are scattered. The leaf surface of Jia58 is also densely covered with papillae, stomata, and other microstructures, and the surface of papillae is smoother. There are ellipsoidal and spherical papillae, with the ellipsoidal papillae being larger and densely arranged along the leaf veins, and the spherical papillae being smaller and scattered. Analyses of leaf surface characteristics showed that the papillae density and leaf wax content were significantly lower in Yongyou12 than in Jia58, while the stomatal density, contact angle, and critical surface tension were higher in Yongyou12 than in Jia58 (Table 3). Glochids were present on the leaf surface of Yongyou12, but not on Jia58. The leaf surface of Yongyou 12 was favourable for the deposition and retention of large droplets on the leaf surface during spraying, while the leaf surface of Jia58 were not. Our results on droplet deposition and distribution were also consistent with this. 


\begin{tabular}{|l|l|l|l|}
\hline \multirow{2}{*}{ Blade surface features } & \multirow{3}{*}{ Unit } & \multicolumn{2}{|l|}{ Cultivar } \\
\cline { 3 - 4 } & & Yongyou12 & Jia58 \\
\hline Papillae density & $10^{3} \mathrm{~mm}^{-2}$ & $6.5 \pm 0.4 \mathrm{~b}$ & $8.5 \pm 0.4 \mathrm{a}$ \\
\hline Stoma density & $\mathrm{A} \mathrm{mm}^{-2}$ & $440 \pm 8.0 \mathrm{a}$ & $390 \pm 12.2 \mathrm{~b}$ \\
\hline Glochid density & $\mathrm{A} \mathrm{mm}^{-2}$ & $6.7 \pm 0.3 \mathrm{a}$ & $0.0 \mathrm{~b}$ \\
\hline Blade wax content & $\mathrm{Mg} \mathrm{cm}^{-2}$ & $1.99 \pm 0.1 \mathrm{~b}$ & $6.04 \pm 0.3 \mathrm{a}$ \\
\hline Critical surface tension & $\mathrm{mN} \mathrm{m}^{-1}$ & $38.8 \pm 8.8 \mathrm{a}$ & $37.9 \pm 7.9 \mathrm{~b}$ \\
\hline
\end{tabular}

Table 3. Characteristics of leaf surface in two rice varieties. The different letters means significant difference $(P \leq 0.01)$ by t-tests.

\section{Discussion}

The microstructure, wax, stomata, and leaf surface attachment hairs and thorns on the surface of plant leaves are more important influencing factors in the process of pesticide droplet deposition ${ }^{15}$. The electron microscope showed that rice leaves were covered with papillary protrusions (papillae) and coated with wax, which specific structure led to strong hydrophobicity of rice leaves ${ }^{16}$. In this study, papillae density of Jia58 was significantly higher compared with Yongyou12. The wax on the surface of the plant greatly affected the droplet wetting and other behaviors, and the C29, C33, and C35 long-chain hydrocarbons in the surface wax of rice leaves were more than $90 \%$, showing strong hydrophobicity ${ }^{17}$. In the study, the leaf surface structure of Jia58 differed greatly from that of Yongyou12, and the content of waxes was significantly higher in Jia58 than in Yongyou12. The epicuticular wax content in the leaves of cabbage (Brassica oleracea) was particularly high, and when spraying in a large volume, the liquid with higher surface tension would easily rebound on the leaves or roll down along the petiole, resulting in lower pesticide utilization ${ }^{18}$. The critical surface tension of glabrous rice was significantly lower than that of hairy-leaved rice, which indicated that the pesticides were not easy to stay on the surface of the leaves of glabrous rice. Finally, the deposition amount per unit leaf area was significantly lower on the glabrous rice Jia58 than on the hairy-leaved rice Yongyou12.

The burrs and thorn attachments on the leaves surface of plant significantly affected the deposition and adhesion behavior of pesticide droplets ${ }^{5,19,20}$. The glochid easily pierced the surface of the droplet, making the contact angle of the droplet on the plant leaf surface smaller ${ }^{21}$. The hairy-leaved rice Yongyou 12 had much glochids on the leaf surface, which increased the leaf surface coverage and promoted the deposition of droplets on the leaf surface (Fig. 1). Song et al. (2013) found that droplets deposited more in silicified bands of rice leaves and mainly on glochids of leaves ${ }^{22}$. On the surface of rice leaves, there are papillae on stomatal band, and there are papillae and glochids on silicified bolt band. The size of glochid was 30-40 times of papillae. The ability of burrs and silicified bolt zone on rice leaf surface to adsorb foreign droplets was significantly stronger than that in other regions, and the droplet attachment accounted for more than $80 \%{ }^{23}$. The number of papilla density and wax content were significantly higher in Jia58 than in Yongyou12, and the glochid density and stoma density of Yongyou12 were lower than those of Jia58, which resulted in significantly lower leaf surface deposition on glabrous rice than on hairy-leaved rice under the same spraying conditions.

The droplet size, droplet volume median diameter, and droplet number median diameter strongly affected droplet deposition ${ }^{20}$. Differences in rice leaf surface properties could lead to different diffusion, aggregation, and even bouncing of droplets on the leaf surface, all of which affected droplet distribution ${ }^{5,19,20}$. In this study, the droplet coverage density was significantly higher on Jia58 than on Yongyou12; the former had smaller droplet diameter, droplet volume median diameter, and droplet number median diameter, and the deposited droplets were smaller but more abundant than those deposited on the leaves of hairy-leaved rice. The critical surface tension of glabrous rice was relatively lower, which surface can be attached to the small particle size droplets with small dynamic surface tension. In pesticide spraying, each droplet had an effective killing radius for pest control, and a certain number of droplets accumulated per unit area could achieve good control effects ${ }^{2,11}$. Compared with hairy-leaved rice, glabrous rice accumulated more small-sized droplets, which reduced the amount of spray solution required for adequate coverage. The leaf surface of hairy-leaved rice was rough, with glochid, which had a larger surface tension and lower wax content. The droplets deposited on it were larger than those deposited on the leaf surface of glabrous rice. Larger pressure and larger flow nozzle were beneficial to the deposition of hairy-leaved rice, while smaller pressure and larger flow nozzle were conducive to the retention of glabrous rice.

Compared with hairy-leaved rice, leaves of glabrous rice lacked trichomes, had a higher wax content and lower critical surface tension. When pesticide was sprayed onto the leaf surface of glabrous rice, the deposition amount was low and the droplets were small with a good coverage density. This means that a lower dosage of pesticides and spray pressures was required for effective pest control in glabrous rice than in hairy-leaved rice. Therefore, when spraying in the field, full consideration should be given to the leaf surface properties of glabrous rice, and the use of lower spray pressure and large flow nozzles could better improve pest control by ensuring adequate, but not excessive, pesticide delivery.

\section{Materials and methods}

Experiment design and plant materials. A pot experiment was conducted at the Experimental Farm, China National Rice Research Institute, Hangzhou, China in 2015. For all experiments on the rice plants, we confirm that all methods were carried out in accordance with relevant guidelines and regulations. Two culti- 


\begin{tabular}{|l|l|l|}
\hline Treatment & Spray pressure $(\mathrm{MPa})$ & Liquid flow $\left(\mathbf{L} \mathbf{~ m i n}^{-\mathbf{1}}\right)$ \\
\hline P1S1 & 0.1 & 1.09 \\
\hline P1S2 & 0.1 & 1.28 \\
\hline P1S3 & 0.1 & 1.62 \\
\hline P2S1 & 0.2 & 1.68 \\
\hline P2S2 & 0.2 & 1.86 \\
\hline P2S3 & 0.2 & 2.14 \\
\hline
\end{tabular}

Table 4. The treatment selected in the spray test and its corresponding spray pressure and liquid flow.

vars were chosen with different leaf surface characteristics. Jia58 with upright leaves, smooth and hairless and Yongyou 12 with upright leaves and hairy leaves were used in the experiment ${ }^{14}$, which were obtained from the Jiaxing Academy of Agricultural Sciences, Zhejiang, China and Ningbo Seed Co., Ltd., China, respectively. The pot experiment was adopted, and the pot size was $20 \mathrm{~cm} \times 18 \mathrm{~cm} \times 25 \mathrm{~cm}$, and each pot contained $8 \mathrm{~kg}$ of soil. The test soil was paddy soil ( $\mathrm{pH} 5.93$, organic matter $28.3 \mathrm{~g} \mathrm{~kg}^{-1}$, total nitrogen $1.6 \mathrm{~g} \mathrm{~kg}^{-1}$, available nitrogen $128.2 \mathrm{mg}$ $\mathrm{kg}^{-1}$, available phosphorus $44.8 \mathrm{mg} \mathrm{kg}^{-1}$, available potassium $130 \mathrm{mg} \mathrm{kg}^{-1}$ ). The nutrient elements were adding at the following proportions in each pot: $200 \mathrm{mg} \mathrm{kg}^{-1} \mathrm{~N}$ (as urea), P $150 \mathrm{mg} \mathrm{kg}^{-1}$ (as Superphosphate), $150 \mathrm{mg}$ $\mathrm{kg}^{-1} \mathrm{~K}$ (as KCl). Irrigation was carried out in accordance with conventional high-yield cultivation methods, intermittent irrigation was used to regularly control the occurrence of pests and diseases, and rice grew normally.

According to Massinon et al. (2014) with minor modifications, the spray device used in this study is a walking spray tower designed and assembled by the China National Rice Research Institute ${ }^{24}$. It included pressure gauges, flow meters, pressure pumps, spray rods, nozzles, etc. The motor drives a uniform speed to travel. The nozzle type, walking speed, spray pressure and spray flow could be adjusted according to the treatment requirements. Two spray pressure treatments (P1, P2) were set in this study. The nozzle type (S1, S2, S3) used in this study is a standard fan nozzle with a spray fan angle of $110^{\circ}$. A total of 6 treatments were set, namely P1S1, P1S2, P1S3, P2S1, P2S2, P2S3 listed in Table 4, and each treatment selected the same population traits and four replicates. The spray agent was a mixed solution of indicator ponceau- $\mathrm{G}$ (mass concentration of $1 \mathrm{~g} \mathrm{~L}^{-1}$ ) and surfactant NP-10 (mass concentration of $150 \mathrm{mg} \mathrm{L}^{-1}$ ) for spray operation. In the rice heading stage, top-pressure spray is used, and the spray nozzle moves parallel from the top of the potted rice, $50 \mathrm{~cm}$ away from the top of the rice. The spray tower kept walking at a constant speed with a speed of $2 \mathrm{~m} \mathrm{~s}^{-1}$. After spraying, single leaves were randomly selected and the image collection device (Sony a7sIII, Sony Corporation, Japan) was used to collect instantaneous images of droplets on the leaf, and 16 single leaves were selected for each process. After the spray liquid was deposited on the surface of the blade and air-dried, separate treatments to collect and sample.

Methods of measurements. Ultrastructure of rice leaf surface. Two freshly fallen leaves at the beginning of the heading stage of the two varieties were selected and fixed with electron microscope fixative, and placed in a refrigerator at $4^{\circ} \mathrm{C}$ for more than $4 \mathrm{~h}$. Rinse 3 times with $0.1 \mathrm{~mol} \mathrm{~L}^{-1} \mathrm{PBS}$ with copper mesh for 15 min each time, then fix with $1 \%$ osmic acid- $0.1 \mathrm{~mol} \mathrm{~L}^{-1} \mathrm{PBS}$ for $30 \mathrm{~min}$, then rinse 3 times with $0.1 \mathrm{~mol} \mathrm{~L}^{-1} \mathrm{PBS}$ for $15 \mathrm{~min}$ each time. Dehydrate in 50-70-80-90-95-100-100\% (v/v) alcohol successively, 15 min each time. Add isoamyl acetate, completely immerse the leaves, let it stand for 10-20 min, and move it into a critical point dryer for drying. Paste the blade or copper mesh on the specimen table with conductive glue (the observation side is facing up), and use a vacuum coating instrument to coat the film (gold film). The sample is placed in a scanning electron microscope for observation, and images are collected for analysis ${ }^{25}$.

Critical surface tension. The contact angle $(\theta)$ of the liquid with the same volume and different surface tension on the surface of the rice leaf at the heading stage was measured with a contact angle measuring instrument. A straight line can be obtained by plotting the $\operatorname{cosine}$ value $\cos \theta$ of the contact angle against the surface tension value of the liquid. Extend the straight line to $\cos \theta=1$, the corresponding liquid surface tension value is the critical surface tension of the rice leaf ${ }^{26}$.

Leaf epidermis wax. Weigh $2 \mathrm{~g}$ of fresh mature leaves, calculate their surface area, and immediately place them in $30 \mathrm{~mL}$ of $60^{\circ} \mathrm{C}$ chloroform, and take them out immediately after $30 \mathrm{~s}$. After the extract is naturally volatilized, weigh the wax mass and calculate the wax content $\left.(\mathrm{ug} \mathrm{cm})^{-2}\right)=$ wax mass $(\mathrm{ug}) /$ wax surface area $\left(\mathrm{cm}^{2}\right)^{27}$.

Droplets deposition. After the spray test, the collected leaves were washed with distilled water and fixed to volume $^{28}$. The absorbance was measured at $510 \mathrm{~nm}$. Weigh $1 \mathrm{~g}$ of Ponceau-G and $150 \mathrm{mg}$ of NP-10, dissolve them with distilled water and transfer them to a $1 \mathrm{~L}$ volumetric flask to make a mixed mother liquor, respectively, to prepare a mixed solution of different mass concentration gradients of Ponceau-G. Measure the absorbance of each concentration solution at $510 \mathrm{~nm}$, and draw a standard curve, the equation is: $\mathrm{y}=18.226 \mathrm{x}-0.7456$ $\left(\mathrm{R}^{2}=0.9994\right)$. According to the standard curve equation and the leaf area, the amount of deposition per unit area of the leaf was calculated.

Leaf droplet group analysis. Leaf area from the digital images collected in the spray test using LA-S plant image analysis system (Wseen detection technology Co., Ltd., Hangzhou, China).The number of droplets and droplet 
area and leaf area from the digital images collected in the spray test using SC-G automatic seed test analysis system (Wseen detection technology Co., Ltd., Hangzhou, China) ${ }^{29}$. The droplet coverage density is the number of droplets deposited on a unit area. The droplet coverage is the ratio of the deposited area on the rice leaf to the leaf area. The droplet diameter is the average diameter of the droplets on the blade. The number median diameter (NMD) refers to the diameter of the droplets arranged on the blade from small to large, and the diameter of the droplets when the number of droplets is accumulated in order from small to large to reach half of the total number of droplets. The volume median diameter (VMD) is the droplet diameter when the volume of the droplets on the blade is added up to half of the total volume of all the droplets in order from small to large $\mathrm{e}^{30}$.

Droplet size analysis. After spraying, the droplets of the rice canopy of each variety of treatment respectively constitute a droplet group. In the droplet group, the average diameter of all droplets is $\mathrm{D}$, grouped by $0-80 \% \mathrm{D}$, $80-160 \% \mathrm{D},>160 \% \mathrm{D}$ (numbers are D1, D2, D3), analyze the distribution of droplets of different sizes in the rice canopy $^{30}$.

Statistical analyses. Statistical analyses were performed by one-way analyses of variance using a general linear model using SPSS 21.0 software. Data are presented as means and standard errors below. Statistically significant differences $(\mathrm{P} \leq 0.05)$ between averages were identified by performing t-tests.

\section{Data availability}

All data generated or analyzed during this study are included in the article.

Received: 26 April 2021; Accepted: 19 August 2021

Published online: 08 September 2021

\section{References}

1. Shen, X., Zhang, L. \& Zhang, J. B. Ratoon rice production in central China: Environmental sustainability and food production. Sci. Total Environ. 764, 142850 (2021).

2. Dong, F. et al. Gramineous weeds near paddy fields are alternative hosts for the Fusarium graminearum species complex that causes fusarium head blight in rice. Plant. Pathol. 69(3), 433-441 (2020).

3. Li, M. J. et al. A combination of rice cultivar mixed-cropping and duck co-culture suppressed weeds and pests in paddy fields. Basic Appl. Ecol. 40, 67-77 (2019).

4. Mary, A. et al. Assessment of biofertilizer use for sustainable agriculture in the Great Mekong Region. J. Environ. Manage. 275, $111300(2020)$

5. Cong, W. F. China’s intercropping leads to higher grain yield gains. Sci. China-Life Sci. 63(10), 1612-1614 (2020).

6. Bao, J. Q. et al. Potential applicability of a cyanobacterium as a biofertilizer and biopesticide in rice fields. Plant Soil 463, 97 (2021).

7. Liu, X. Y. et al. Managing herbicide resistance in China. Weed Sci. 69(1), 4-17 (2021).

8. Zhang, S. T. et al. Remediation of organochlorine pesticide-contaminated soils by surfactant-enhanced washing combined with activated carbon selective adsorption. Pedosphere 29(3), 400-408 (2019).

9. Zhang, W. et al. Wind tunnel experimental study on droplet drift reduction by a conical electrostatic nozzle for pesticide spraying. Int. J. Agric. Biol. Eng. 10(3), 87-94 (2017).

10. Wang, Y. H. et al. Imidacloprid susceptibility survey and selection risk assessment in field populations of Nilaparvata lugens. J. Econ. Entomol. 101(2), 515-522 (2008).

11. Sheehy, J. E., Dionora, M. J. A. \& Mitchell, P. L. Spikelet numbers, sink size and potential yield in rice. Field Crop Res. 71(2), 77-85 (2001).

12. Smith, D. B. et al. Droplet size and leaf morphology effects on pesticide spray deposition. Trans. ASAE 43(2), 255-259 (2000).

13. Nuyttens, D. et al. Effect of nozzle type, size and pressure on spray droplet characteristics. Biosyst. Eng. 97, 333-345 (2007).

14. Li, J. J. et al. Study on sensitivity of glabrous rice to pest insects and diseases. Acta Agric. Jiangxi 25(3), 50-53 (2013).

15. Kumar, N. et al. Do leaf surface characteristics affect Agrobacterium infection in tea [Camellia sinensis (L.) O Kuntze]? J. Biosci. 29(3), 309-317 (2004).

16. Islam, M.T. et al. Epidermal features of rice leaf cv. BRRI dhan 29. Bangl. J. Plant Taxon. 16(2), 177-180 (2009).

17. Haque, M. M., Mackill, J. D. \& Ingram, K. T. Inheritance of leaf epicuticular wax content in rice. Crop Sci. 32, 865-868 (1992).

18. Znidarcic, D., Valic, N. \& Trdan, S. Epicuticular wax content in the leaves of cabbage (Brassica oleracea L. var. capitata) as a mechanical barrier against three insect pests. Acta Agric. Slovenica 91(2), 361-370 (2008).

19. Li, J. et al. Effects of leaf response velocity on spray deposition with an air-assisted orchard sprayer. Int. J. Agric. Biol. Eng. 14(1), 123-132 (2021).

20. Widyastuti, L. P. Y., Suwarno, W. B. \& Aswidinnoor, H. Genotype by environment analysis on multi-canopy cropping system towards vertical harvest space in rice. Agron. J. 112(6), 4568-4577 (2020).

21. Yu, Y. et al. Evaporation and coverage area of pesticide droplets on hairy and waxy leaves. Biosyst. Eng. 104, 324-334 (2009).

22. Song, J. L. et al. Deposition part analysis and microscopic test of spray droplets on rice leaves. Trans. Chin. Soc. Agric. Mach. 44(4), $54-58$ (2013).

23. Wu, D. et al. The adhesion rule of plant protection uav fog drops on rice leaf surface. J. Agric. Mech. Res. 1, 189-194 (2020).

24. Massinon, M., Boukhalfa, H. \& Lebeau, F. The effect of surface orientation on spray retention. Precis. Agric. 15, 241-254 (2014).

25. Muller, C. \& Riederer, M. Plant surface properties in chemical ecology. J. Chem. Ecol. 31(11), 2621-2651 (2005).

26. Byer, K. N. et al. Spray retention and its effect on weed control by herbicides. Biol. Control 37(3), 307-313 (2009).

27. Zhou, X. et al. Overexpression of transcription factor OsWR2 regulates wax and cutin biosynthesis in rice and enhances its tolerance to water deficit. Plant Mol. Biol. Rep. 32(3), 719-731 (2014).

28. Maski, D. \& Durairaj, D. Effects of charging voltage, application speed, target height, and orientation upon charged spray deposition on leaf abaxial and adaxial surfaces. Crop Prot. 29, 134-141 (2010).

29. Salyani, M. \& Fox, R. D. Performance of image analysis for assessment of simulated spray droplet distribution. Trans. ASAE 37(4), 1083-1089 (1994).

30. $\mathrm{Xu}, \mathrm{D}$. J. et al. Influence of spray method on the deposit and distribution of spray droplets in rice field. Sci. Agric. Sin. 47(1), 69-79 (2014). 


\section{Acknowledgements}

This work was supported by the National Natural Science Foundation (31471416), Agricultural Scientific and Technological Innovation project of Chinese Academy of Agricultural Sciences (206030204YF0520), Special Funds for the Construction of Modern Agricultural Research System (CARS-01-22), the Basic Research Foundation of National Commonweal Research Institute (2017RG004-4) and Key Research and Development Plan of Zhejiang Province (2019C02017).

\section{Author contributions}

Y.K.Z. and D.F.Z. conceived the project and designed the experiment. G.M.J. and Z.G.W. performed the experiment and analyzed the data. H.Z.C., Y.P.Z., J.X. and Y.L.W. provided assistance in collecting and pretreated the samples. G.M.J. and Y.K.Z. wrote the paper. All authors reviewed the manuscript.

\section{Competing interests}

The authors declare no competing interests.

\section{Additional information \\ Correspondence and requests for materials should be addressed to D.Z. or Y.Z.}

Reprints and permissions information is available at www.nature.com/reprints.

Publisher's note Springer Nature remains neutral with regard to jurisdictional claims in published maps and institutional affiliations.

(c) (i) Open Access This article is licensed under a Creative Commons Attribution 4.0 International License, which permits use, sharing, adaptation, distribution and reproduction in any medium or format, as long as you give appropriate credit to the original author(s) and the source, provide a link to the Creative Commons licence, and indicate if changes were made. The images or other third party material in this article are included in the article's Creative Commons licence, unless indicated otherwise in a credit line to the material. If material is not included in the article's Creative Commons licence and your intended use is not permitted by statutory regulation or exceeds the permitted use, you will need to obtain permission directly from the copyright holder. To view a copy of this licence, visit http://creativecommons.org/licenses/by/4.0/.

(C) The Author(s) 2021 